\title{
Application of high-resolution thermal infrared remote sensing and GIS to assess the urban heat island effect
}

\author{
C. P. LO \\ Department of Geography, University of Georgia, Athens, Georgia 30602,
} U.S.A.

\section{A. QUATTROCHI and J. C. LUVALL}

NASA. Earth System Science Division, Global Hydrology and Climate Center, ES 41, Marshall Space Flight Center, Huntsville, Alabama 35812, U.S.A.

\author{
(Received 10 January 1996; in final form 11 June 1996)
}

\begin{abstract}
Day and night airborne thermal infrared image data at $5 \mathrm{~m}$ spatial resolution acquired with the 15-channel $(0.45 \mu \mathrm{m}-12.2 \mu \mathrm{m})$ Advanced Thermal and Land Applications Sensor (ATLAS) over Alabama, Huntsville on 7 September, 1994 were used to study changes in the thermal signatures of urban land cover types between day and night. Thermal channel number 13 $(9.60 \mu \mathrm{m}-10.2 \mu \mathrm{m})$ data with the best noise-equivalent temperature change (NE $\triangle \mathrm{T}$ ) of $0.25^{\circ} \mathrm{C}$ after atmospheric corrections and temperature calibration were selected for use in this analysis. This research also examined the relation between land cover irradiance and vegetation amount, using the Normalized Difference Vegetation Index (NDVI), obtained by ratioing the difference and the sum of the red (channel number 3: 0.60-0.63 $\mu \mathrm{m}$ ) and reflected infrared (channel number 6: $0 \cdot 76-0.90 \mu \mathrm{m}$ ) ATLAS data. Based on the mean radiance values, standard deviations, and NDVI extracted from 351 pairs of polygons of day and night channel number 13 images for the city of Huntsville, a spatial model of warming and cooling characteristics of commercial, residential, agricultural, vegetation. and water features was developed using a GIS approach. There is a strong negative correlation between NDVI and irradiance of residential, agricultural, and vacant/transitional land cover types, indicating that the irradiance of a land cover type is greatly influenced by the amount of vegetation present. The predominance of forests, agricultural, and residential uses associated with varying degrees of tree cover showed great contrasts with commercial and services land cover types in the centre of the city, and favours the development of urban heat islands. The high-resolution thermal infrared images match the complexity of the urban environment, and are capable of characterizing accurately the urban land cover types for the spatial modeling of the urban heat island effect using a GIS approach.
\end{abstract}

\section{Introduction}

The main objective of this research is to apply airborne high-resolution thermal infrared imagery to study the phenomenon of the urban heat island, using Huntsville, Alabama, a medium-sized American city, as the study area. The occurrence of urban heat islands represents human-induced urban/rural contrast, which is caused by deforestation and the replacement of the land surface by non-evaporating and nonporous materials such as asphalt and concrete. The result is reduced evapotranspiration and more rapid runoff of rain water (Carlson 1986, Kim 1992). The urban landscape forms a canopy acting as a transitional zone between the atmosphere and the land surface. The composition and structure of this canopy have a significant 
impact on the thermal behaviour of the urban environment (Goward 1981). In other words, apart from the properties of urban construction materials, the layout of buildings and pavements within an urban landscape can also affect the appearance of the urban heat island (Oke 1987).

Research on the trends of surface temperatures at rapidly growing urban sites in the U.S.A. during the last 30 to 50 years suggests that significant urban heat island effects have caused the temperatures at these sites to rise by 1 to $2^{\circ} \mathrm{C}$ (Cayan and Douglas 1984, Karl et al. 1988). Urban heat islands have caused changes in urban precipitation and temperature that are at least similar to, if not greater than, those predicted to develop over the next 100 years by global change models (Changnon 1992).

Satellite remote sensing, particularly NOAA AVHRR data, has been used in the study of urban heat islands (e.g., Lee 1993, Matson et al. 1978, Brest 1987, Gallo et al. 1993, Roth et al. 1989). Because of the low spatial resolution $(1 \cdot 1 \mathrm{~km}$ at nadir) of the AVHRR data, these studies can only examine and map the phenomenon at the macro-level. As Roth et al. (1989) observed, the heterogeneity of the urban environment rendered the definition of this surface very difficult, and the smoothing of signals within a pixel introduced bias in the radiant temperatures extracted. Recently, Nichol (1994) has successfully utilized Landsat Thematic Mapper (TM) thermal infrared data (with a spatial resolution of $120 \mathrm{~m}$ ) to derive surface temperature data for some housing estates in Singapore. But the spatial resolution of the TM thermal infrared data is still inadequate to capture all the complex temperature changes of the urban environment.

This research utilized $5 \mathrm{~m}$ thermal infrared data acquired specially from an aircraft to characterize more accurately the thermal responses of different land cover types in the urban environment as input to urban heat island detection.

\section{Data acquisition and processing}

The thermal infrared data were acquired by the Lockheed Engineering and Science Company as Mission M424 over the greater Huntsville, Alabama area, on 7, September 1994, a clear day with less than 5 per cent of cloud cover in the sky, using the Advanced Thermal and Land Applications Sensor (ATLAS) sensor system on board a NASA Stennis LearJet. The ATLAS is a 15-channel imaging system which incorporates the bandwidths of the Landsat Thematic Mapper with additional bands in the middle reflective infrared and thermal infrared range (table 1). All 15-channel data were acquired on the same date at $10 \mathrm{~m}$ and $5 \mathrm{~m}$ resolutions. To optimize the detection of warming and cooling of urban land surfaces, the image data were planned to be acquired first around solar noon $(12: 00-13: 00)$ and then repeated $2-3 \mathrm{~h}$ after sunset. In all, starting from 11:00 Central Time, nine daytime flight lines were flown from an altitude of $5000 \mathrm{~m}$ to image at $10 \mathrm{~m}$ resolution, and six daytime flight lines were flown from an altitude of $2500 \mathrm{~m}$ to image at $5 \mathrm{~m}$ resolution. All these flight lines were repeated at night beginning at 20:30. Central Time. Colour infrared aerial (CIR) photography was also acquired simultaneously using a Zeiss aerial camera (with $152 \mathrm{~mm}$ focal length and $23 \mathrm{~cm} \times 23 \mathrm{~cm}$ photograph format) during the daytime flights. Ground data collection, including the establishment of GPS ground control points, measurement of surface temperatures at selected sites of different cover types throughout the city, and the concurrent launches of radiosonde were also carried out at the time of overflights. In addition, meteorological station data were obtained from the Army at Redstone Arsenal and at Marshall 
Table 1. ATLAS system specifications.

\begin{tabular}{|c|c|c|c|c|c|}
\hline Channel & $\begin{array}{l}\text { Band width } \\
\text { limits }(\mu \mathrm{m})\end{array}$ & $\begin{array}{c}\text { NER } \\
\mathrm{mW} / \mathrm{cm}^{-2}(\mu \mathrm{m})\end{array}$ & $\underset{{ }^{N} \mathrm{C}}{\mathrm{NE} \Delta \mathrm{T}}$ & $\begin{array}{c}\text { MTF@ } \\
2 \mathrm{mrad}\end{array}$ & Cooling \\
\hline 1 & $0.45-0.52$ & $<0.008$ & $\mathrm{~N} / \mathrm{A}$ & 0.5 & Ambient \\
\hline 2 & $0.52-0.60$ & $<0.004$ & $N / A$ & 0.5 & Ambient \\
\hline 3 & $0.60-0.63$ & $<0.006$ & $\mathrm{~N} / \mathrm{A}$ & 0.5 & Ambient \\
\hline 4 & $0.63-0.69$ & $<0.004$ & $\mathrm{~N} / \mathrm{A}$ & 0.5 & Ambient \\
\hline 5 & $0.69-0.76$ & $<0.004$ & $\mathrm{~N} / \mathrm{A}$ & 0.5 & Ambient \\
\hline 6 & $0.76-0.90$ & $<0.005$ & $\mathrm{~N} / \mathrm{A}$ & 0.5 & Ambient \\
\hline 7 & $1.55-1.75$ & $<0.05$ & $N / A$ & 0.5 & $77 \mathrm{~K}$ \\
\hline 8 & $2 \cdot 08-2 \cdot 35$ & $<0.05$ & $N / A$ & 0.5 & $77 \mathrm{~K}$ \\
\hline 9 & $3 \cdot 35-4 \cdot 20$ & $\mathrm{~N} / \mathrm{A}$ & $<0.3$ & 0.5 & $77 \mathrm{~K}$ \\
\hline 10 & $8 \cdot 20-8 \cdot 60$ & $\mathrm{~N} / \mathrm{A}$ & $<0.2$ & 0.5 & $77 \mathrm{~K}$ \\
\hline 11 & $8 \cdot 60-9 \cdot 00$ & $\mathrm{~N} / \mathrm{A}$ & $<0.2$ & 0.5 & $77 \mathrm{~K}$ \\
\hline 12 & $9 \cdot 00-9 \cdot 40$ & $\mathrm{~N} / \mathrm{A}$ & $<0.2$ & 0.5 & $77 \mathrm{~K}$ \\
\hline 13 & $9 \cdot 60-10 \cdot 2$ & $\mathrm{~N} / \mathrm{A}$ & $<0.2$ & 0.5 & $77 \mathrm{~K}$ \\
\hline 14 & $10 \cdot 2-11 \cdot 2$ & $\mathrm{~N} / \mathrm{A}$ & $<0.2$ & 0.5 & $77 \mathrm{~K}$ \\
\hline 15 & $11 \cdot 2-12 \cdot 2$ & $\mathrm{~N} / \mathrm{A}$ & $<0.3$ & 0.5 & $77 \mathrm{~K}$ \\
\hline
\end{tabular}

Space Flight Center during overflights. The Portable Ground Atmospheric Measurement System (PGAMS) was also used to collect data for atmospheric correction. Altogether over $10 \mathrm{~Gb}$ of digital image data were obtained by this flight mission. Despite some glitches in channels 7,8 , and 9 (the mid-infrared channels) and some smears in channel 3 , the overall quality of these digital data, particularly the thermal infrared data of channels 10 to 15 , was judged to be very good. The CIR photography is excellent in quality, and, because of its superior spatial resolution, provides 'ground truth' information against which the digital image data can be checked.

For this particular research, the focus has been on the six thermal infrared bands (channels 10 to 15 , in the spectral range from $8.20 \mu \mathrm{m}$ to $12.2 \mu \mathrm{m}$; table 1 ). These data have recorded long-wave radiation emitted by both the natural and artificial surfaces in the city of Huntsville. The original image data recorded the radiation as digital number (DN) in 8-bit format with integer values ranging from 0 to 255 . Before these image data can be used, they have first to be corrected for the attenuation effect of the atmosphere, namely, transmittance and path radiance, and second, to be calibrated to produce accurate temperature measurements. Atmospheric correction was achieved by applying the MODTRAN program developed by the United States Air Force Geophysics Laboratory, which estimates atmospheric transmittance and radiance for a given atmospheric path at moderate spectral resolution over the operational wavelength region from 0.25 to $28.5 \mu \mathrm{m}$ calculated in $1 \mathrm{~cm}^{-1}$ frequency interval (Berk et al. 1989). The input parameters to the program for the atmospheric correction are the radiosonde data of atmospheric profiles during the ATLAS overflights. Temperature calibration of the ATLAS sensor for each channel was achieved by using onboard low and high temperature blackbodies which were referenced at the beginning and end of each scan line. With a knowledge of the emittance value for the blackbodies, Planck's equation was applied to calculate the ATLAS reference blackbody radiance for each channel of the sensor system. By combining the outputs of the MODTRAN atmospheric correction program with the high and low blackbodies temperature calibration of the ATLAS sensor system, the Earth Resources 
Laboratory Applications Software (ELAS) module TRADE (TIMS < CAMS, ATLAS > Radiant Energy) computed the system transfer equation (STE), withinchannel normalization, atmospheric correction, and the conversion of the 8-bit DN of each pixel of the image data into 32-bit atmospheric radiance in units of $\mathrm{W} \mathrm{cm}^{-2}$ $\mathrm{sr}^{-1} \mu \mathrm{m}^{-1}$ (Graham et al. 1986, Luvall et al. 1990, Anderson 1992).

In this paper, to provide a better appreciation of the thermal characteristics of the land cover type, radiance is converted into irradiance, or radiant flux density incident on a surface in $\mathrm{W} \mathrm{m}^{-2}$ (Monteith 1973). The use of energy values avoids the need for emissivity correction for land cover in the case where temperature values are used.

This research will make use of the high-resolution $5 \mathrm{~m}$ ATLAS data only because the complexity of human activities in the urban environment requires the highest possible spatial resolution for an accurate characterization of the urban land cover's thermal responses. In the next phase of the research, the $10 \mathrm{~m}$ resolution data will also be employed for comparative study and to determine the optimum spatial resolution. In view of the need to produce a false colour composite image and to compute the Normalized Difference Vegetation Index (NDVI), four channels of data: channel $2(0.52-0.60 \mu \mathrm{m}$ : visible green $)$, channel $3(0.60-0.63 \mu \mathrm{m}$ : visible red $)$, channel $6(0.76-0.93 \mu \mathrm{m}$ : reflected infrared), and channel $13(9.60-10 \cdot 2 \mu \mathrm{m}$ : thermal infrared) were extracted from the six flight lines acquired in the daytime, and one thermal channel (13) from the corresponding six flight lines acquired at night.

Channel $13(9 \cdot 60-10 \cdot 2 \mu \mathrm{m})$ is the thermal band of choice mainly because after the atmospheric correction and temperature calibration, channel 13 data exhibit the best noise-equivalent temperature change (NE $\Delta \mathrm{T}$ ) of $0.25^{\circ} \mathrm{C}$ (i.e., the temperature change across the target that would produce a signal-to-noise ratio of unity in the detector output). According to Wien's Law, the surface temperatures recordable within the waveband limits of channel 13 are from 284 to $301 \mathrm{~K}$. In other words, the waveband limits of channel 13 display the maximum energy per unit wavelength of terrestrial radiation. Image data from the other three channels: channel 2 $(0.52-0.60 \mu \mathrm{m})$, the green band, channel $3(0.60-0.63 \mu \mathrm{m})$ the red band, and channel 6 $(0.76-0.90 \mu \mathrm{m})$, the reflected infrared band, when displayed through the blue, green, and red guns of the computer monitor respectively as overlays, will produce a false colour composite image (simulating the colour infrared) which emphasizes vegetation vigour. When channel 2 data are displayed in green, channel 6 data are displayed in red, and channel 13, the thermal band, data are displayed in blue, the false colour composite image produced will also pinpoint hot and cool objects distinctly, in addition to indicating the vigor of the vegetation (figure 1). As for the night-time imagery, images can be recorded clearly only in the six thermal bands. A night-time image of channel 13 is shown in figure 2.

\section{The study area}

The city of Huntsville, located in north Alabama, is not a typical American city. Two dominating land uses within the city are the Redstone Arsenal and the Marshall Space Flight Center of NASA, both related to the U.S. Government. It is also the site for the campus of the University of Alabama in Huntsville (UAH). Services and industries are attracted here to serve them. Many of these are high-tech in nature, such as Intergraph, and their locations in the city are quite distinct. The city has developed spacious sites to locate these offices and industries in the form of a 'research park', developed over agricultural land. These offices are often intermingled 


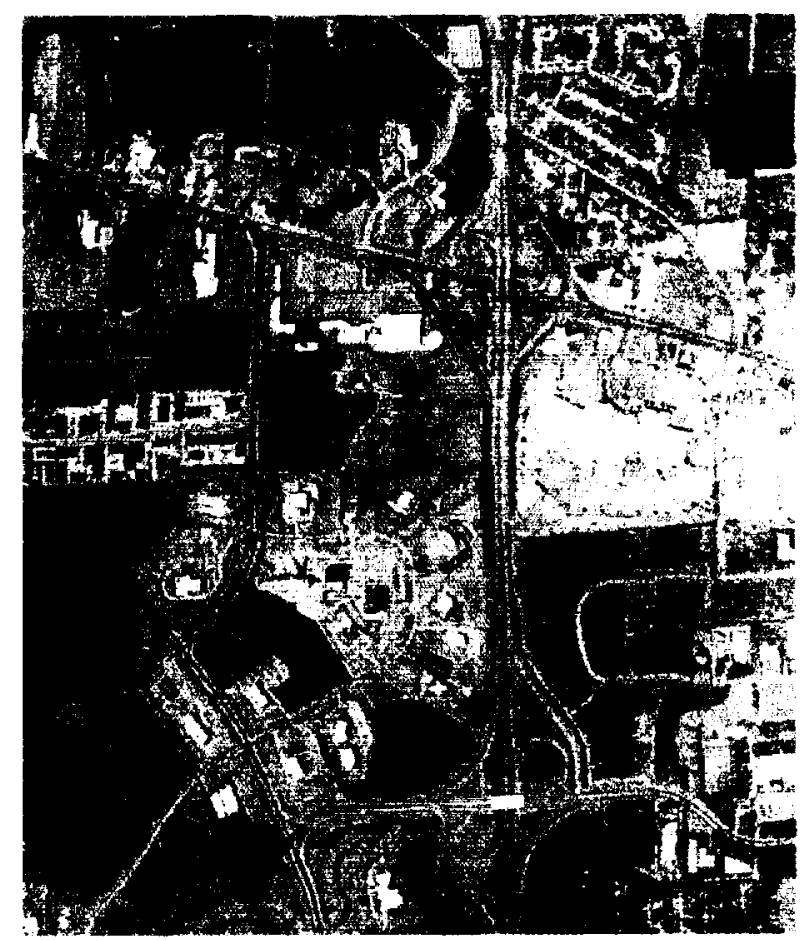

Figure 1. A false colour composite of the Madison Square Mall area of Huntsville, Alabama. formed by displaying channel $2(0.52-0.60 \mu \mathrm{m})$ image in green, channel $6(0.76-0.90 \mu \mathrm{m})$ image in red, and channel $13(9 \cdot 60-10 \cdot 2 \mu \mathrm{m})$ image in blue. Colour changes from white, yellow, pink, orange, red, light blue, dark blue, and black, indicating changes of irradiance from very high to very low.

with croplands of soybeans, cotton, and corn. The city does not have a large central business district (CBD). However, the street pattern in the CBD is more dense and distinct. The city is well served by highways and roads, the most important of which are Interstate 565, Highway 72, and Memorial Parkway (Highway 231/431). Topographically, the city is also quite unique. Located at an average elevation of $236 \mathrm{~m}$, the city's eastern extent is limited by a north-south running barrier of mountains: Huntsville Mountain, Green Mountain, and Wallace Mountain. Its northern extent is marked by Smither Mountain and Wade Mountain. Southeast of the city is the Ward Mountain. Its southern extent is marked by the Tennessee River and its associated lakes and tributaries, where wetlands occur in abundance. It is interesting to know how such a combination of landforms and human activities has affected the development of the urban heat island.

\section{Analysis}

In order to make the best use of the high-resolution thermal infrared data, the characteristics of the thermal signatures of each land cover type in the city of Huntsville were studied. With the aid of the ELAS image processing software running on a Silicon Graphics (SG) workstation, the daytime and night-time images of the city was displayed simultaneously. A key of land cover types with codes was developed (table 2). From the displayed images, representative polygons of each land 


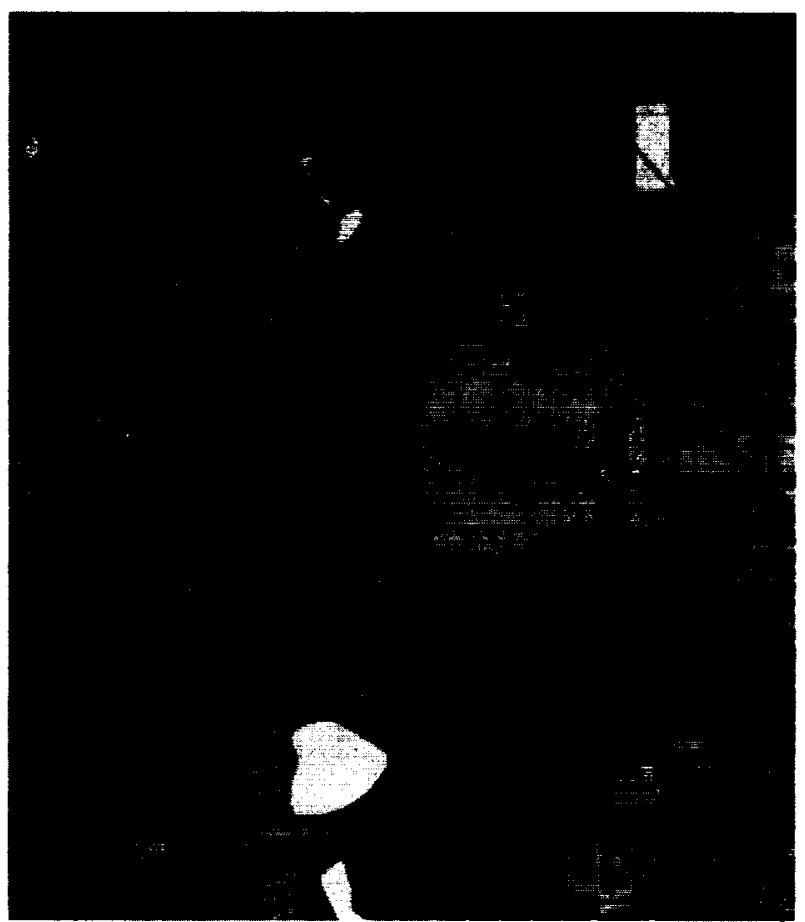

Figure 2. Night-time channel number $13(9 \cdot 60-10 \cdot 2 \mu \mathrm{m})$ image of the Madison Square Mall area of Huntsville. Black indicates low irradiance and white indicates high irradiance.

cover type were manually delineated from both the daytime and night-time images, in the same manner as training sets are delineated in a supervised image classification. The mean irradiance values and standard deviations of these polygons were extracted from the images. A total of 351 pairs of polygons were extracted.

Because the urban heat island is related to the reduction of evapotranspiration from surface vegetation cover, it is useful to know the relationship between surface vegetation cover and water availability. Recent research has shown that NDVI is a good indicator of surface radiant temperature (Nemani and Running 1989, Gillies and Carlson 1995). NDVI for the city of Huntsville is therefore computed from the daytime image data using the following formula:

$$
\mathrm{NDVI}=(\operatorname{ch} 6-\operatorname{ch} 3) /(\operatorname{ch} 6+\operatorname{ch} 3)
$$

where ch 3 is the red band $(0.60-0.63 \mu \mathrm{m})$ and ch6 is the reflected infrared band $(0.76-0.90 \mu \mathrm{m})$ of the image data. The NDVIs were computed for each of the land cover polygons extracted from the daytime images.

\section{Results}

\subsection{Day and night contrasts in irradiance}

The average irradiance values by land cover types are summarized in table 3 . It is clear that during the daytime, commercial land cover types exhibit the highest irradiance (above $70 \mathrm{Wm}^{-2}$ ), followed by services $\left(65-70 \mathrm{Wm}^{-2}\right)$, transportation $\left(57-74 \mathrm{Wm}^{-2}\right)$, and industrial uses $\left(63-69 \mathrm{Wm}^{-2}\right)$. The standard deviations (SDs) of the daytime irradiance values are high, indicating the heterogeneous nature of these land cover types. By contrast, the lowest daytime irradiance is found in water 
Table 2. Land use/cover key for Huntsville, Alabama, U.S.A.

1. Residential (RE)

a single family homes with $>50 \%$ and of tree canopy

b single family homes with between $50 \%$ to $10 \%$ tree canopy

c single family homes with $<10 \%$ tree canopy

d multi-unit dwellings (apartments/condominiums) (generally without much vegetation canopy)

2. Commercial (CO)
a retailing (large)

b retailing (small)

3. Services (SE)
a offices (high-rises): high density
b offices (low buildings): low density
c schools and universities
d other institutions (government or private), e.g. NASA

4. Industrial ( $\mathrm{MN}$ )
a light
b heavy
c warehouse

5. Agriculture (AG)
a cropland with row crops growing
b cropland harvested/fallowed; not currently used
c pasture

6. Transportation (TR)
a interstate highways
b state highways
c bridges
d air fields (civilian and military)
e parking lots

7. Vegetation (VE)
a coniferous forests
$b$ deciduous forests
c mixed coniferous and deciduous
d grass
e wetland vegetation (visible)

8. Water bodies (MA)
a rivers and streams
$b$ ponds, lakes, and reservoirs
c wetland (no vegetation visible)

9. Recreational/open space (RC)

a golf courses

b parks

c baseball fields/stadiums

10. Vacant or transitional (VA)

bodies (54-59 $\left.\mathrm{Wm}^{-2}\right)$ followed by vegetation $\left(55-62 \mathrm{Wm}^{-2}\right)$ and agriculture $\left(55-62 \mathrm{Wm}^{-2}\right)$. Residential uses occupy an intermediate position in irradiance $\left(62-69 \mathrm{Wm}^{-2}\right)$ because they are composed of buildings and tree cover in varying degrees of mixture.

At night, commercial, services, industrial, and transportation land cover types cool down rapidly to very similar irradiance values $\left(45-47 \mathrm{Wm}^{-2}\right)$ so that they are not too much higher than those for vegetation and agriculture (table 3 ). Water is 
Table 3. Average irradiance by land cover types for day and night.

\begin{tabular}{|c|c|c|c|c|c|}
\hline $\begin{array}{l}\text { Land cover type } \\
\text { (see key in table 2) }\end{array}$ & $\begin{array}{c}\text { Day } \\
\mathrm{Wm}^{-2}\end{array}$ & $\begin{array}{l}\text { Day:SD } \\
\mathrm{Wm}^{-2}\end{array}$ & $\begin{array}{l}\text { Night } \\
\mathrm{Wm}^{-2}\end{array}$ & $\begin{array}{c}\text { Night:SD } \\
\mathrm{Wm}^{-2}\end{array}$ & $\begin{array}{c}\text { Diff. between day \& } \\
\text { night } \\
W^{-2}\end{array}$ \\
\hline 1. Residential (RE) & $65 \cdot 44$ & $8 \cdot 21$ & $45 \cdot 53$ & 1.97 & $19 \cdot 92$ \\
\hline $\mathrm{REa}$ & $61 \cdot 85$ & $7 \cdot 88$ & $45 \cdot 13$ & $1 \cdot 48$ & $16 \cdot 72$ \\
\hline $\mathrm{REb}$ & $64 \cdot 50$ & $8 \cdot 78$ & $45 \cdot 94$ & 1.92 & $18 \cdot 56$ \\
\hline REc & $65 \cdot 98$ & $7 \cdot 55$ & $44 \cdot 55$ & $2 \cdot 18$ & $21 \cdot 42$ \\
\hline REd & $68 \cdot 94$ & $8 \cdot 33$ & $46 \cdot 01$ & $2 \cdot 30$ & $22 \cdot 92$ \\
\hline 2. Commercial (CO) & $70 \cdot 90$ & 7.99 & $46 \cdot 26$ & $4 \cdot 31$ & $24 \cdot 64$ \\
\hline $\mathrm{COa}$ & $71 \cdot 48$ & $7 \cdot 56$ & 46.51 & $4 \cdot 33$ & 24.97 \\
\hline $\mathrm{COb}$ & $70 \cdot 37$ & $8 \cdot 38$ & $46 \cdot 03$ & $4 \cdot 29$ & $24 \cdot 33$ \\
\hline 3. Services (SE) & $68 \cdot 35$ & 6.99 & $45 \cdot 95$ & $3 \cdot 40$ & $22 \cdot 40$ \\
\hline SEa & $65 \cdot 32$ & $8 \cdot 13$ & $45 \cdot 41$ & 1.97 & $19 \cdot 91$ \\
\hline $\mathrm{SEb}$ & $69 \cdot 27$ & $7 \cdot 85$ & 44.92 & $4 \cdot 05$ & $24 \cdot 36$ \\
\hline $\mathrm{SEc}$ & $70 \cdot 31$ & $7 \cdot 85$ & 46.02 & $3 \cdot 30$ & $24 \cdot 29$ \\
\hline SEd & $66 \cdot 79$ & $6 \cdot 24$ & $45 \cdot 89$ & 3.43 & $20 \cdot 90$ \\
\hline 4. Industrial (MN) & $66 \cdot 09$ & 6.55 & $44 \cdot 85$ & $3 \cdot 28$ & $21 \cdot 24$ \\
\hline $\mathrm{MNa}$ & $68 \cdot 90$ & $7 \cdot 10$ & $45 \cdot 04$ & 3.57 & $23 \cdot 85$ \\
\hline $\mathrm{MNb}$ & $63 \cdot 32$ & $4 \cdot 56$ & $47 \cdot 51$ & 1.63 & $15 \cdot 81$ \\
\hline $\mathrm{MNc}$ & 63.65 & 6.90 & 43.06 & $3 \cdot 80$ & $20 \cdot 60$ \\
\hline 5. Agriculture (AG) & $58 \cdot 26$ & 1.09 & $\mathbf{4 3 \cdot 2 0}$ & 0.51 & $15 \cdot 06$ \\
\hline $\mathrm{AGa}$ & $55 \cdot 20$ & $1 \cdot 10$ & $42 \cdot 33$ & 0.51 & $12 \cdot 86$ \\
\hline $\mathrm{AGb}$ & 61.77 & 1.00 & 43.99 & 0.41 & $17 \cdot 77$ \\
\hline $\mathrm{AGc}$ & 57.93 & $1 \cdot 14$ & $43 \cdot 22$ & 0.56 & $14 \cdot 70$ \\
\hline 6. Transport (TR) & $67 \cdot 73$ & 4.53 & $47 \cdot 45$ & 1.69 & $20 \cdot 27$ \\
\hline TRa & 67.92 & $7 \cdot 52$ & $45 \cdot 56$ & $3 \cdot 19$ & $22 \cdot 37$ \\
\hline $\mathrm{TRb}$ & $69 \cdot 30$ & 3.96 & $48 \cdot 08$ & 1.38 & $21 \cdot 22$ \\
\hline TRe & $57 \cdot 16$ & $2 \cdot 75$ & $46 \cdot 48$ & $2 \cdot 04$ & $10 \cdot 68$ \\
\hline TRd & $64 \cdot 55$ & $5 \cdot 23$ & 44.90 & $2 \cdot 43$ & $19 \cdot 66$ \\
\hline $\mathrm{TRe}$ & 73.69 & $4 \cdot 41$ & $49 \cdot 33$ & 1.05 & $24 \cdot 37$ \\
\hline 7. Vegetation (VE) & 56.90 & $0 \cdot 88$ & $45 \cdot 56$ & 0.57 & $10 \cdot 34$ \\
\hline $\mathrm{VEa}$ & $54 \cdot 93$ & 0.63 & $45 \cdot 28$ & 0.35 & 9.66 \\
\hline $\mathrm{VEb}$ & $54 \cdot 62$ & $0 \cdot 76$ & $44 \cdot 35$ & 0.40 & $10 \cdot 28$ \\
\hline VEc & $54 \cdot 88$ & $0 \cdot 77$ & $45 \cdot 18$ & 0.43 & $9 \cdot 71$ \\
\hline VEd & $61 \cdot 62$ & $1 \cdot 34$ & $44 \cdot 49$ & 0.79 & $17 \cdot 13$ \\
\hline VEe & $57 \cdot 63$ & $1 \cdot 18$ & 47.07 & 0.98 & $10 \cdot 56$ \\
\hline 8. Water (WA) & $55 \cdot 21$ & 0.44 & $52 \cdot 33$ & $0 \cdot 40$ & $2 \cdot 89$ \\
\hline WAa & $54 \cdot 41$ & $0 \cdot 27$ & $53 \cdot 33$ & $0 \cdot 28$ & 1.09 \\
\hline WAb & $55 \cdot 68$ & 0.42 & 51.62 & 0.35 & 4.06 \\
\hline WAc & $58 \cdot 68$ & 1.77 & $48 \cdot 50$ & $1 \cdot 54$ & $10 \cdot 19$ \\
\hline 9. Recreational (RC) & $63 \cdot 03$ & $3 \cdot 78$ & $45 \cdot 61$ & $1 \cdot 47$ & $17 \cdot 42$ \\
\hline $\mathrm{RCa}$ & $61 \cdot 40$ & $2 \cdot 51$ & $44 \cdot 66$ & 0.96 & $16 \cdot 74$ \\
\hline $\mathrm{RCb}$ & $63 \cdot 16$ & 3.90 & $44 \cdot 95$ & $1 \cdot 28$ & $18 \cdot 21$ \\
\hline $\mathrm{RCc}$ & $71 \cdot 79$ & $5 \cdot 67$ & $48 \cdot 13$ & $2 \cdot 31$ & 23.66 \\
\hline $\mathrm{RCd}$ & $60 \cdot 04$ & $3 \cdot 43$ & $44 \cdot 28$ & $1 \cdot 08$ & $15 \cdot 75$ \\
\hline 10. Vacant (VA) & $60 \cdot 88$ & $2 \cdot 27$ & $44 \cdot 35$ & 0.93 & $16 \cdot 53$ \\
\hline
\end{tabular}

the only land cover type that shows the highest irradiance values at night $\left(52-54 \mathrm{Wm}^{-2}\right)$, while agriculture exhibits the lowest at night. In other words, all the different categories of land cover are cooler at night than during the day. By virtue of their homogeneity, the land cover types of water, vegetation, and agriculture exhibit small SDs in their irradiance values at night as compared with commercial, services, and industrial land cover types. Residential uses, which are again inter- 
mediate in position in irradiance at night $\left(45-46 \mathrm{Wm}^{-2}\right)$, show much less variation than that during the day.

Because each broad class of land cover comprises sub-classes of distinctive characteristics, their irradiance values vary. In residential uses, multi-unit dwellings (such as apartments and condominiums, coded as REd in tables 2 and 3) show higher daytime irradiance value $\left(69 \mathrm{Wm}^{-2}\right)$ than single-family houses with tree covers (such as, REa with $>50$ per cent of tree canopy and REb with $50-10$ per cent tree canopy, which exhibit 62 and $65 \mathrm{Wm}^{-2}$ respectively). The higher percentage of tree cover results in lower irradiance during the daytime. At night, the difference in irradiance among the four subclasses of residential uses is much smaller than that in the daytime (varying from 45 to $46 \mathrm{Wm}^{-2}$ only). In agricultural uses, harvested and fallowed land $(\mathrm{AGb})$ shows much higher irradiance in the daytime than row crop land $(\mathrm{AGa})$ and pasture land $(\mathrm{AGc})$ (table 3). At night, while all show lower irradiance, the contrast between harvested fields and cropped areas is very much reduced $\left(42-44 \mathrm{Wm}^{-2}\right)$. As for the vegetation cover, there is a predominance of mixed coniferous and deciduous trees (VEc) in the city, mostly on the mountains and along the rivers. They show higher irradiance $\left(55 \mathrm{Wm}^{-2}\right)$ in the daytime and much lower irradiance $\left(45 \mathrm{Wm}^{-2}\right)$ at night. Grass cover (VEd) shows the highest irradiance $\left(62 \mathrm{Wm}^{-2}\right)$ during the day but much lower irradiance $\left(45 \mathrm{Wm}^{-2}\right)$ at night. As a result, grass cover registers the highest day-night irradiance differential $\left(17 \mathrm{Wm}^{-2}\right)$ in the vegetation land cover category. The most noteworthy is the wetland vegetation (VEe), which is intermediate in day-time irradiance between forests and grass, but it shows much higher irradiance than other types of vegetation at night probably because of its association with water.

For services land cover types, schools and universities (SEc) show higher irradiance $\left(70 \mathrm{Wm}^{-2}\right)$ during the day than other services classes (table 3$)$. The government uses (SEd, mostly located in Marshall Space Flight Center and Redstone Arsenal) also exhibit high daytime irradiance $\left(67 \mathrm{Wm}^{-2}\right)$. At night, the irradiance values of these uses are much more similar $\left(46 \mathrm{Wm}^{-2}\right)$. It should be noted that offices housed in high-rise buildings ( $\mathrm{SEa}$ ) register lower irradiance values $\left(65 \mathrm{Wm}^{-2}\right)$ than offices housed in low buildings (SEb) $\left(69 \mathrm{Wm}^{-2}\right)$, suggesting that landscaping may have helped to lower the irradiance. For commercial uses, large shopping malls (COa) show slightly higher irradiance $\left(72 \mathrm{Wm}^{-2}\right)$ than small shopping centres $(\mathrm{COb})$ $\left(70 \mathrm{Wm}^{-2}\right)$ in the daytime, but both types of commercial uses show much lower but very similar irradiance at night $\left(46-47 \mathrm{Wm}^{-2}\right.$; table 3$)$. Industrial uses exhibit higher irradiance for light industrial uses ( $\mathrm{MNa}$ with $69 \mathrm{Wm}^{-2}$ ) but lower irradiance for heavy industrial uses $(\mathrm{MNb})$ and warehouse uses $(\mathrm{MNc})\left(63\right.$ and $64 \mathrm{Wm}^{-2}$ respectively). At night, heavy industrial uses $(\mathrm{MNa})$ show the highest irradiance of the three with $48 \mathrm{Wm}^{-2}$ as compared with $43 \mathrm{Wm}^{-2}$ for warehouse uses and $45 \mathrm{Wm}^{-2}$ for light industrial uses, so that there are some significant night-time differences among these three classes of industrial use (table 3 ).

Many of these commercial and industrial areas have buildings with aluminum roofs which possess very low emissivities (i.e., very high reflectance). Hence, they cool off very rapidly at night. In contrast with the services, commercial, and industrial land cover types, water (with emissivity close to unity) shows little difference in irradiance during the day and at night. However, wetland (WAc) exhibits the highest irradiance $\left(59 \mathrm{Wm}^{-2}\right)$ in the daytime and the lowest irradiance $\left(49 \mathrm{Wm}^{-2}\right)$ at night. Lakes (WAb) show slightly higher irradiance $\left(56 \mathrm{Wm}^{-2}\right)$ than rivers and streams (WAa) $\left(55 \mathrm{Wm}^{-2}\right)$ during the day but lower irradiance $\left(52 \mathrm{Wm}^{-2}\right)$ than rivers and streams $\left(53 \mathrm{Wm}^{-2}\right)$ at night. 


\subsection{Relations between NDVI and irradiance of land cover types}

The value of NDVI varies from -1 to +1 indicating the amount of vegetation (biomass) that is found in the land cover polygon. In this research, the relation between the irradiance of the land cover type and the amount of vegetation (as represented by NDVI) is investigated. The Pearson's correlation coefficients were computed between the NDVI of each broad land cover type and its irradiance. The significance of each correlation coefficient was determined using a one-tail Student's $t$-test. Table 4 indicates that NDVI values tend to be correlated negatively with the irradiance of all broad land use types for both day and night with the exception of water, which is correlated positively with the irradiance during the day, but negatively at night. The highest negative correlation during the day is with the irradiance of transitional or vacant $(-0.94)$, residential $(-0.86)$, agricultural $(-0.84)$, and vegetation $(-0.74)$ land, all at 99.9 per cent or higher level of confidence. Services uses also exhibit a lower but equally significant correlation ( -0.75$)$. At night, NDVI shows the strongest negative correlation with the irradiance of recreation land $(-0.91)$ at 99.9 per cent level of confidence, although significant (at 99.9 per cent level) negative correlations are also observed for water ( -0.69$)$, agricultural $(-0.60)$, vegetation $(-0.58)$, and services $(-0.51)$ uses. The fact that the irradiance values of services uses exhibit significant correlation with NDVI values for both day and night indicates the occurrence of a green environment for the location of offices in Huntsville.

The NDVI's very strong (but negatively correlated) relationship with the irradiance of residential, agricultural, vegetation, and vacant/transitional uses implies that the higher vegetation amount which characterize these uses can bring down the surface temperatures in that land cover type. In other words, residential, agricultural, vegetation, and some vacant/transitional land uses in the city of Huntsville are conducive to the lowering of daytime surface temperatures. At night, residential land is less effective than agricultural and transitional land in lowering the surface temperature as indicated by the insignificant negative correlation between residential use with NDVI at night (table 4).

Plots of commercial, industrial, and transportation uses against NDVI (figure 3) are distinctly different from those for residential, agricultural, and vacant/transitional

Table 4. Pearson's correlation coefficients between NDVI and day- and night-time irradiance of the broad classes of land cover in the city of Huntsville, Alabama, U.S.A.

\begin{tabular}{lccc}
\hline Land cover class & $\begin{array}{c}\text { Number of } \\
\text { polygons }\end{array}$ & $\begin{array}{c}R \\
\text { (daytime) }\end{array}$ & $\begin{array}{c}R \\
\text { (night-time) }\end{array}$ \\
\hline 1. Agricultural & 64 & $-0 \cdot 8367^{*}$ & $-0.6022^{*}$ \\
2. Commercial & 31 & $-0 \cdot 3556$ & $-0 \cdot 1460$ \\
3. Industrial & 21 & $-0 \cdot 4674$ & $-0 \cdot 1946$ \\
4. Recreational & 11 & $-0 \cdot 6799$ & $-0 \cdot 9073$ \\
5. Residential & 68 & $-0 \cdot 8590^{*}$ & $-0 \cdot 2416$ \\
6. Services & 41 & $-0 \cdot 7470^{*}$ & $-0 \cdot 5047^{*}$ \\
7. Transportation & 12 & $-0 \cdot 1069$ & $-0 \cdot 4850$ \\
8. Vacant/transitional & 20 & $-0.9435^{*}$ & $-0 \cdot 2031$ \\
9. Vegetation & 57 & $-0 \cdot 7428^{*}$ & $-0 \cdot 5759^{*}$ \\
10. Water & 24 & $+0 \cdot 6756^{*}$ & $-0 \cdot 6943^{*}$ \\
\hline
\end{tabular}
t-test.

* indicates significance level at 99.9 per cent determined by Student's 

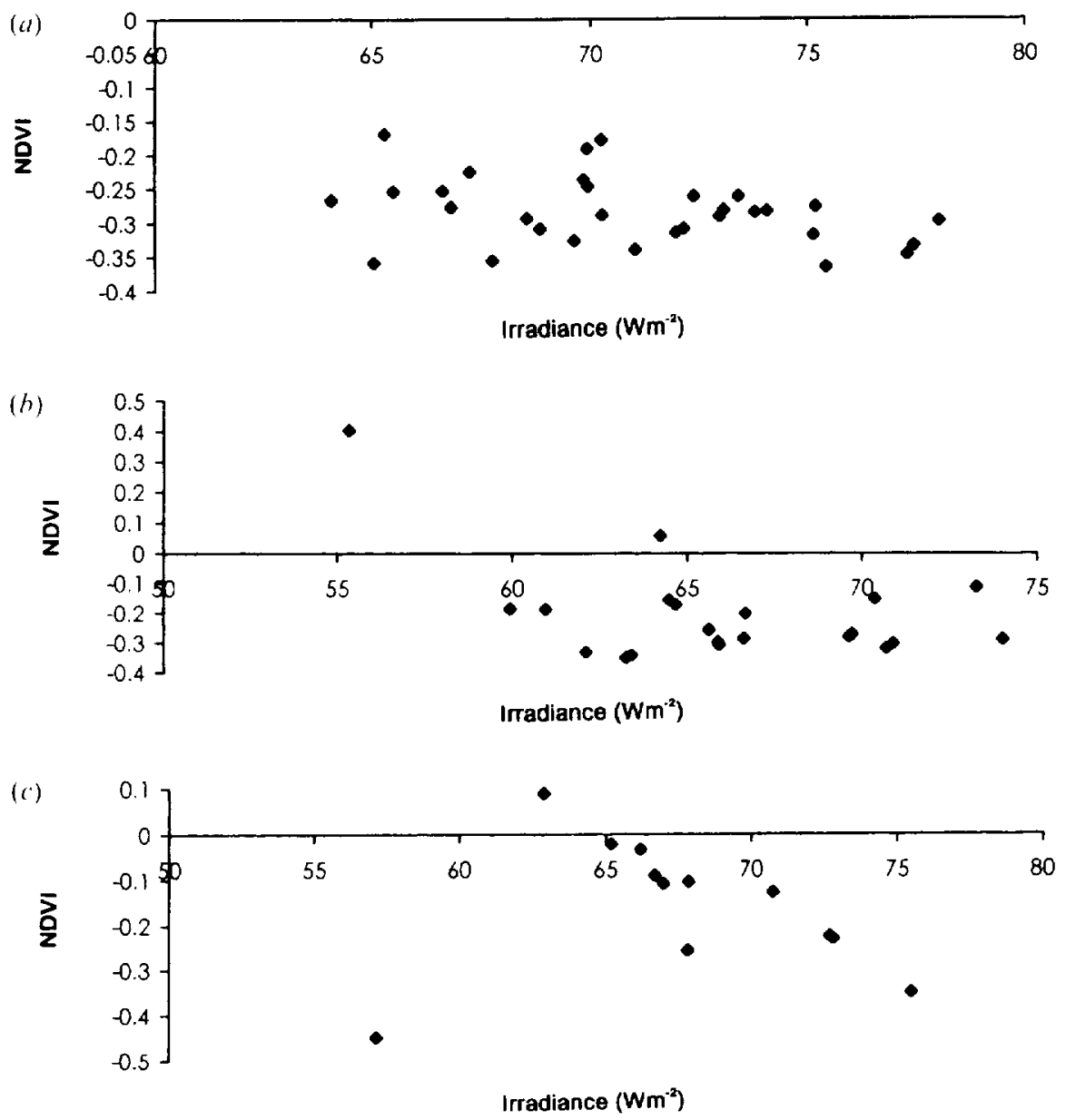

Figure 3. Scatter plots of NDVI versus irradiance from $(a)$ commercial; $(b)$ industrial; and (c) transportation land cover types.

uses (figure 4) in that they occupy the quadrant with negative NDVIs, an indication that they do not have a lot of vegetation amount to help lower their surface temperatures. This is particularly worse for the commercial land use.

Services that show a moderately strong negative correlation with NDVI for both day and night are in a mixed group. In some types of services uses, such as offices in low-density areas (the research park) as well as schools and universities, some vegetation is associated with them, which gives rise to higher NDVI. The military and government uses included in this broad category of services are more mixed in character, which range from office buildings in Marshall Space Flight Center to missile testing ranges in Redstone Arsenal. But as a group, services uses are associated with much more vegetation than commercial and industrial uses.

The very strong relationship between NDVI and residential and agricultural uses prompts the authors to perform a linear regression analysis. For the relationship between NDVI and residential uses, the adjusted $R^{2}$ value is 0.73 based on 68 

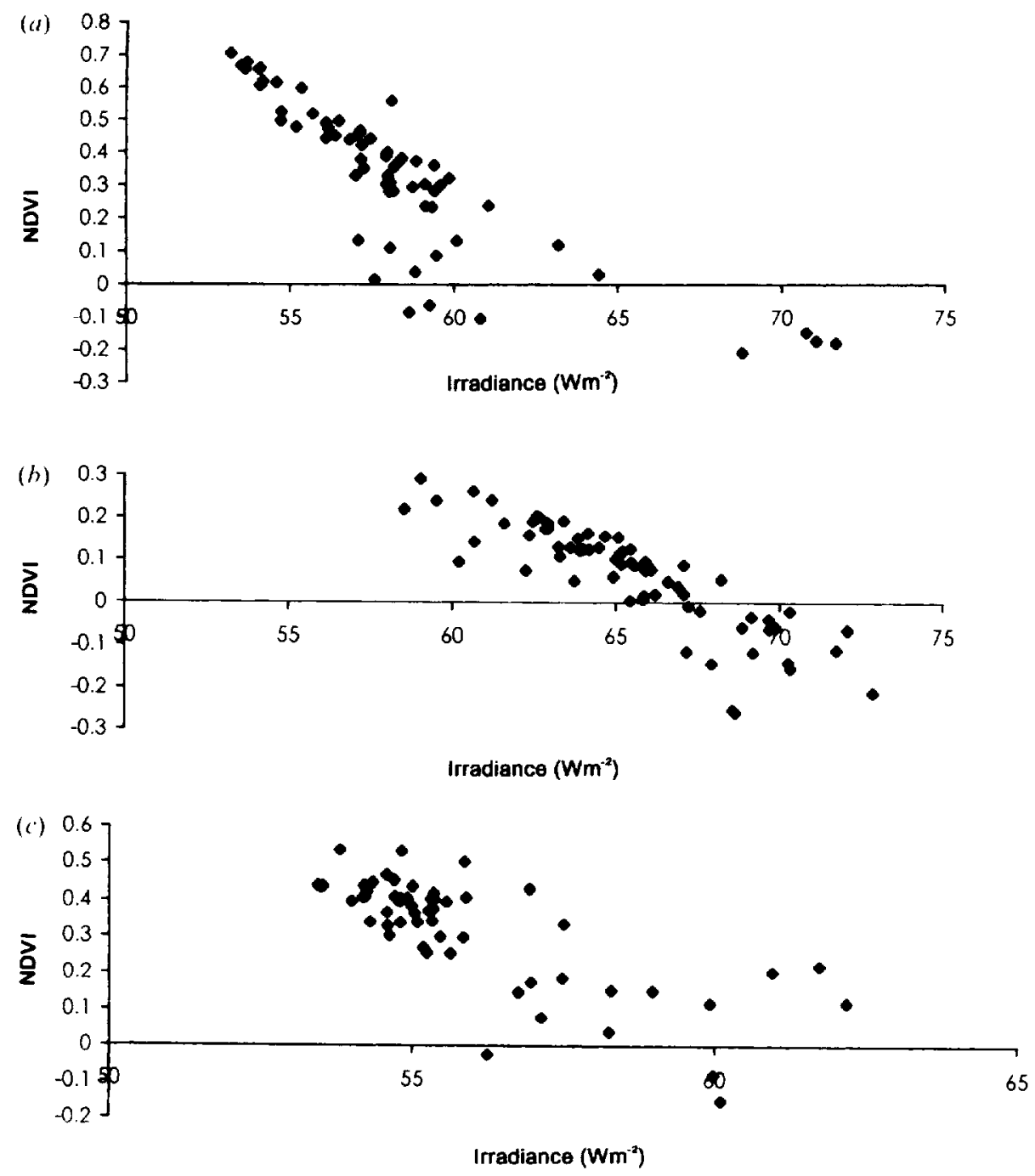

Figure 4. Scatter plots of NDVI versus irradiance from $(a)$ agricultural; $(b)$ residential; and (c) vegetation land cover types.

polygons. The linear model developed takes the following form:

$$
Y_{\text {ire }}=66 \cdot 87-22 \cdot 30\left(X_{\text {ndvi }}\right)
$$

or conversely:

$$
Y_{\text {ndvi }}=2 \cdot 23-0 \cdot 03\left(X_{\text {ire }}\right)
$$

where $Y_{\text {ire }}$ or $X_{\text {ire }}$ and $X_{\text {ndvi }}$ or $Y_{\text {ndvi }}$ are irradiance and NDVI for residential land cover respectively.

Similarly, for agricultural uses, the adjusted $R^{2}$ value is 0.70 based on 64 polygons. The linear regression equation is:

$$
Y_{\text {iaq }}=62.87-13.91\left(X_{\text {ndvi }}\right)
$$


or conversely,

$$
Y_{\text {ndvi }}=3.26-0.05\left(X_{\text {iaq }}\right)
$$

where $Y_{\text {iag }}$ or $X_{\text {iag }}$, and $X_{\text {ndvi }}$ or $Y_{\text {ndvi }}$ are irradiance and NDVI for agricultural land cover type respectively.

By using these equations, the irradiance of residential and agricultural uses can be predicted based on NDVI (or vice versa). Regression equations such as these are useful because thermal infrared data are not always available, while NDVIs which are derived from image data in the visible and reflected infrared bands are more easy to obtain. Thus, NDVI is a surrogate of the irradiance of a land cover type, from which some ideas of the surface temperatures of the land cover type can be obtained.

6. Development of a spatial model of an urban heat island for Huntsville using GIS

A land use/cover map of the city of Huntsville can be obtained from a visual interpretation of the CIR aerial photographs (figure 5). This map was digitized and then converted into the raster format and georeferenced. Because each land cover type has a distinctive thermal signature during the day and at night, as revealed by the findings in this research, the digital land use/cover map can be converted into a

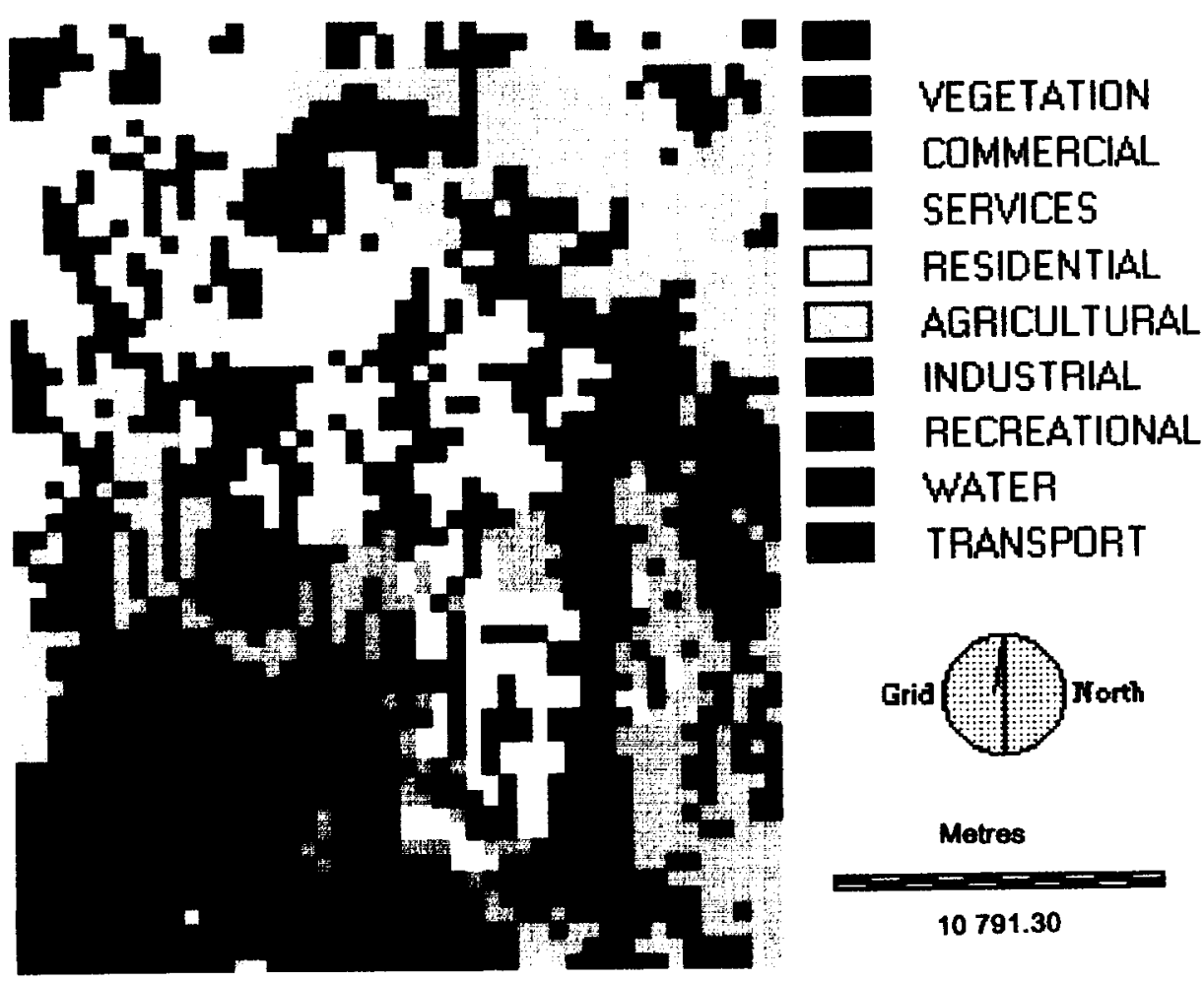

Figure 5. Land use cover map of Huntsville. The UTM co-ordinates of the map extent are: (1) upper corner: $525300 \mathrm{~m} \mathrm{E}$ and $3856700 \mathrm{~m} \mathrm{~N}$ : (2) upper right corner: $550800 \mathrm{~m} \mathrm{E}$ and $3856700 \mathrm{~m} \mathrm{~N}$; (3) lower left corner: $525300 \mathrm{~m} \mathrm{E}$ and $3822800 \mathrm{~m} \mathrm{~N}$ : and (4) lower right corner: $550800 \mathrm{mE}$ and $3822800 \mathrm{~m} \mathrm{~N}$. The five black pixels are control points used to register this map with other layers of data. 
map of irradiance, one for the day (figure 6) and one for the night (figure 7), using the 'assign attribute' function of the GIS. The degree of detail mapped depends on the level of classification scheme used for land use/cover interpretation. By using high-resolution aerial photography at the scale of $1: 15000$, very detailed land use/cover map ( Level III/IV) can be obtained by manual interpretation. For simplicity, this research just makes use of the average thermal signatures of the 10 broad classes of land use/cover of Huntsville (table 3). By drawing profiles (such as the $\mathrm{N}-\mathrm{S}$ and $\mathrm{E}-\mathrm{W}$ ones), with the aid of the GIS software, one sees the occurrences of numerous 'peaks' from the centre of the city outward during the daytime and at night (figures 8 and 9). However, during the night time, the 'peaks' in the day have become 'troughs' (figures 8 and 9). The night and day irradiance difference map reveals that these troughs are in the centre of the city where most commercial and service uses occur (figure 10). Huntsville is characterized by the occurrence of agricultural land cover ( 30.9 per cent) and forests ( 35.9 per cent) in the periphery as well as inside the city. Residential uses ( 16.8 per cent) are also associated with tree cover. Commercial ( 2.0 per cent) and services ( 7.6 per cent) uses are small compared to the other uses. The spatial pattern of these different land use/cover classes can affect the development of urban heat islands. It seems that the layout of land use/cover for the city of Huntsville favours the development of urban heat island not only as a difference in temperature between the city centre and its periphery, but also among

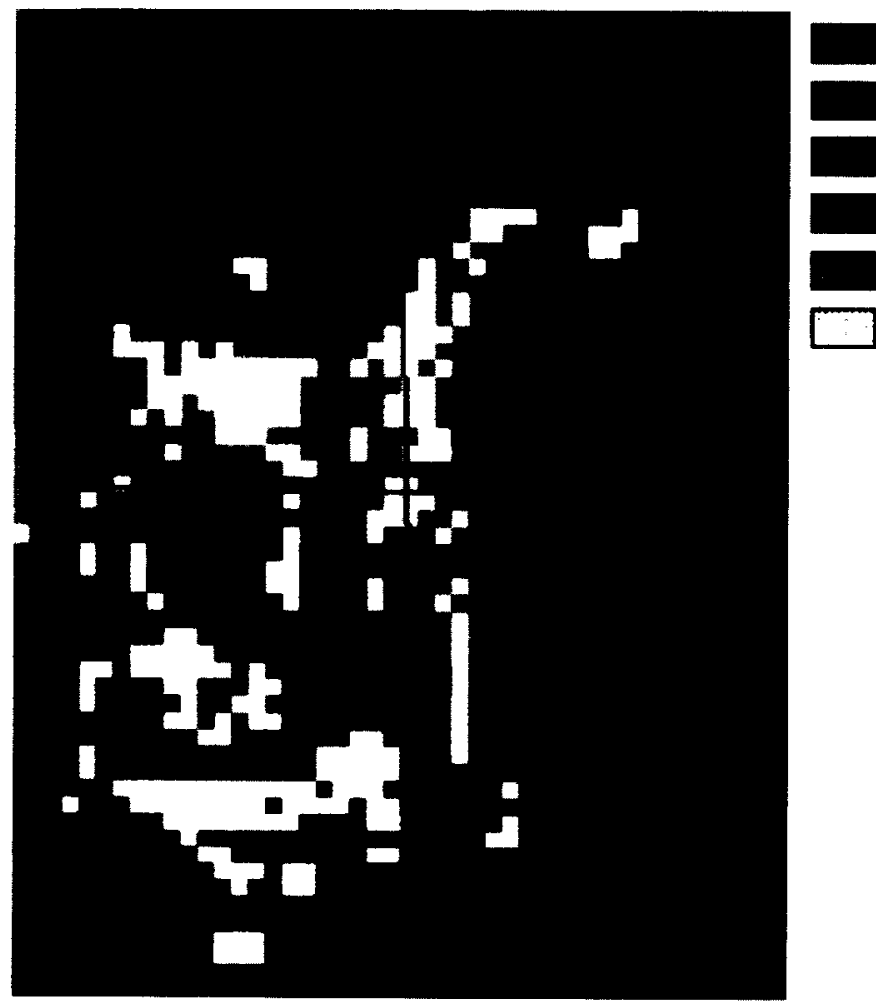

Figure 6. Daytime irradiance map (in $\mathrm{Wm}^{-2}$ ) of Huntsville. The $\mathrm{E} \mathrm{W}$ and $\mathrm{N}-\mathrm{S}$ cross section lines for figures 8 and 9 are indicated. The five black pixels are control points used to register this map with other layers of data. 


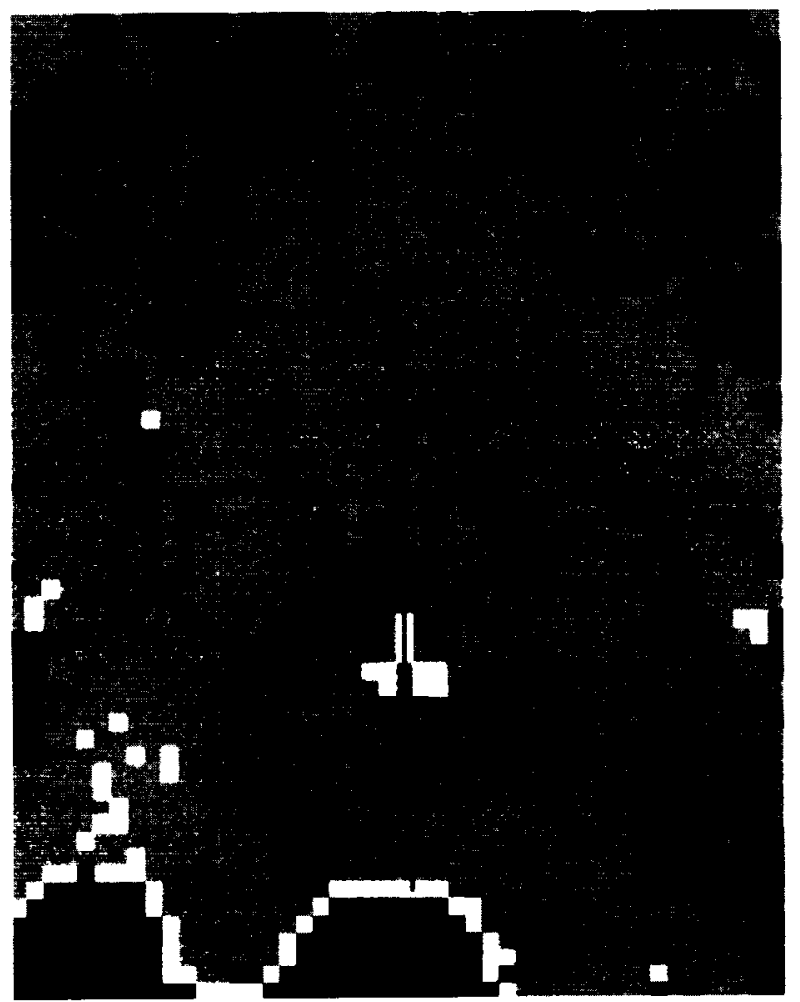

Figure 7. Night-time irradiance map (in $\mathrm{Wm}^{-2}$ ) of Huntsville. The $\mathrm{E}-\mathrm{W}$ and $\mathrm{N}-\mathrm{S}$ cross section lines for figures 8 and 9 are indicated. The five black pixels are control points used to register this map with other layers of data.

agricultural, vegetation, and commercial uses in the whole city, thus giving rise to the emergence of many small urban heat islands throughout the city. Such a development is enhanced by the topographic characteristics of Huntsville, which may have also induced radiation fog to the warmer residential areas at the lower level at night as revealed by the flight line of channel 13 image along the eastern part of the city where mountains predominate.

\section{Conclusions}

There are some important findings from this research. High-resolution thermal infrared image data acquired from the ATLAS sensor system after correction for atmospheric transmittance and path radiance followed by blackbodies temperature calibration produce radiance values in 32-bit accuracy for the assessment of the urban heat island effect. Thermal signatures of different land cover types in the city for day and night help to shed light on their roles in contributing to the urban heat island phenomenon. It was found that commercial, industrial, and services uses exhibit the highest daytime irradiance while water, agriculture, and vegetation the lowest. Water, which shows very small day-night difference in irradiance, stands out unique as being the coolest in the daytime and the warmest at night because it possesses very high emissivity. Residential uses occupy an intermediate position because of their varying degrees of association with tree cover. A study of the 


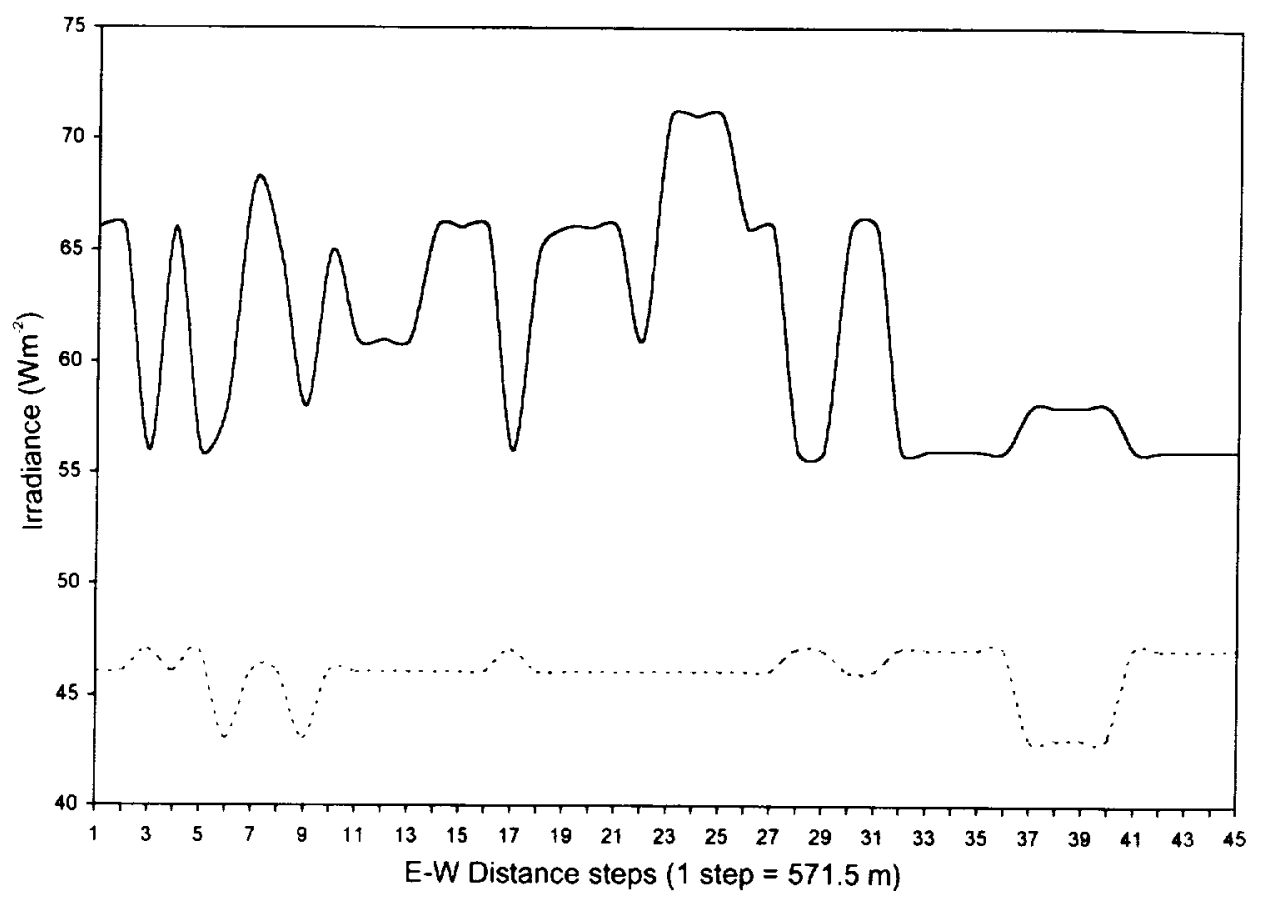

Figure 8. E-W profiles across - daytime and -.- night-time irradiance maps in figures 6 and 7 .

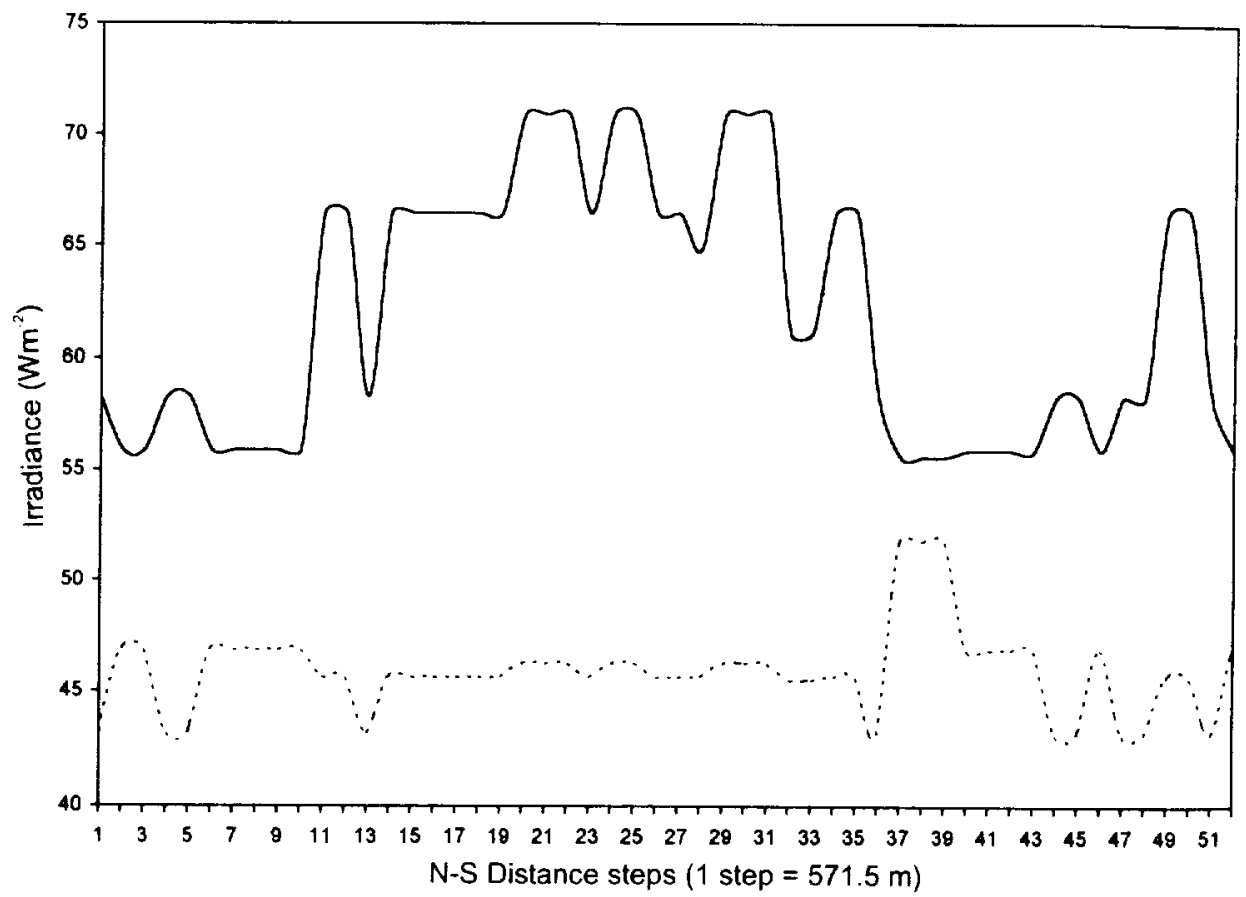

Figure 9. $\mathrm{N}-\mathrm{S}$ profiles across - daytime and -.- night-time irradiance maps in figures 6 and 7 . 


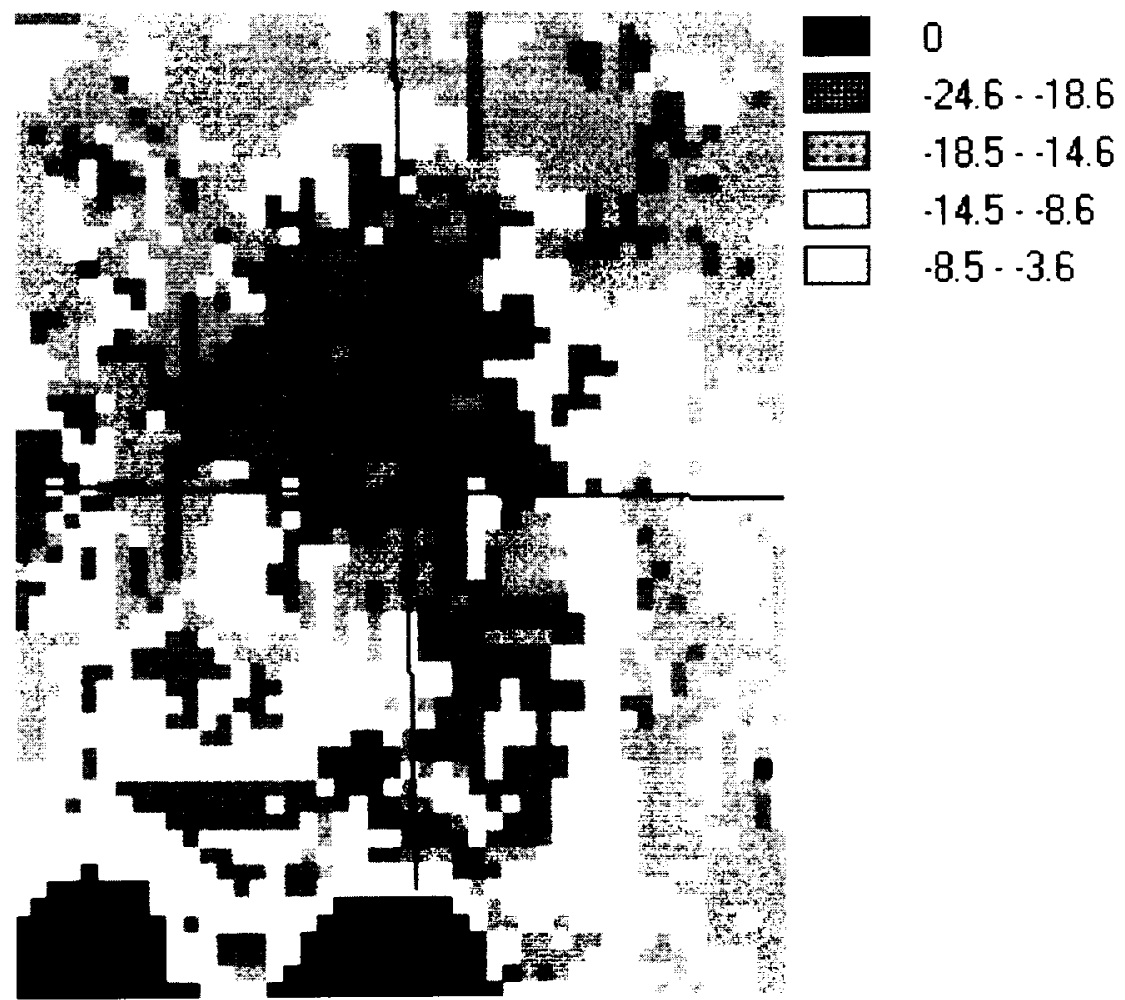

Figure 10. Night-day irradiance difference map (in $\mathrm{Wm}^{-2}$ ) of Huntsville.

relationship between NDVI (as a surrogate of vegetation amount) and the irradiance of each category of land cover (as a surrogate of surface temperature) reveals the importance of vacant transitional, residential, agricultural, and vegetation land cover types in contributing towards lowering their surface temperatures by virtue of their association with biomass. Based on their strong negative correlations, regression equations can be developed to predict the irradiance of the residential and agricultural land cover types from NDVIs.

Based on a broad land use/cover map interpreted from aerial photographs, a spatial model of urban heat island for Huntsville has been developed by substituting in the thermal signatures associated with the land cover types. The model suggests that favourable conditions exist in Huntsville for the development of pockets of daynight temperature differences either between the city centre and the periphery, or among contrasting land cover types inside the city. The spatial layout of the land use/cover in a city has a great impact on the development of heat islands. Therefore, urban planning can be applied to avert or alleviate the effect of urban heat islands (McPherson 1994).

Finally, the high-resolution thermal infrared image data permit detailed characterization of the highly complex urban land cover types and hence a more realistic assessment of the urban heat island effect.

\section{Acknowledgements}

C. P. Lo was awarded the summer faculty research fellowship by NASA for 1994 and 1995 , which made possible his research reported in this paper. Dale Quattrochi 
and Jeffrey Luvall acknowledge the financial support of NASA MSFC Center Director's Discretionary Fund support which made possible the acquisition of the high-resolution ATLAS data, ground data collection, and data analysis required for this research. The authors are grateful to the comments of two anonymous reviewers for improving an earlier draft of this paper.

\section{References}

ANDERSON, J. E., 1992, Determination of water surface temperature based on the use of thermal infrared multispectral scanner data. Geocarto International, 3, 3-8.

Berk. A. L., Bernstein, L. S. and Robertson, D. C., 1989, modtran: a Moderate Resolution Model for LOWTRAN 7 (Hanscom Air Force Base, MA 01731-5000: Geophysics Laboratory, Air Force Systems Command, United States Air Force).

BREST, C. L., 1987, Seasonal albedo of an urban/rural landscape from satellite observations. Journal of Climate and Applied Meteorology, 26, 1169-1187.

CARLSON, T. N.. 1986, Regional-scale estimates of surface moisture availability and thermal inertia using remote thermal measurements. Remote Sensing Reviews, 1, 197-247.

CaYAN, D. R. and Douglas, A. V., 1984, Urban influences on surface temperatures in the southwestern United States during recent decades. Journal of Climate and Applied Meteorology, 23, 1520-1530.

ChANGNON, S. A., 1992, Inadvertent weather modification in urban areas: lessons for global climate change. Bulletin of the American Meterological Society, 73, 621-627.

Gallo, K. P., MCNab, A. L., Karl, T. R., Brown, J. F., Hood, J. J., and Tarpley, J. D., 1993. The use of a vegetation index for assessment of the urban heat island effect. International Journal of Remote Sensing, 14, 2223-2230.

GiLLIES, R. R. and CARLSON, T. N., 1995, Thermal remote sensing of surface soil water content with partial vegetation cover for incorporation into climate models. Journal of Applied Meteorology, 34, 745-756.

GowaRd, S. N., 1981, Thermal behavior of urban landscapes and the urban heat island. Physical Geography, 2, 19-33.

Graham, M. H., Junkin, B. G., Kalcic, M. T., Pearson, R. W., and Seyfarth, B. R., 1986, ELAS-Earth Resources Laboratory Applications Software; revised January 1986. NASA/NSTL/ERL Report No. 183; Earth Resource Laboratory, NASA.

Karl, T. R., Diaz, H. F., and KuKLA, G., 1988, Urbanization: its detection and effect in the United States climate record, Journal of Climate, 1, 1099-1123.

KIM, H. H., 1992, Urban heat island. International Journal of Remote Sensing, 13, 319-2336.

LEE, H. Y., 1993, An application of NOAA AVHRR thermal data to the study of urban heat islands. Atmospheric Environment, 27B, 1-13.

Luvall. J. C., Lieberman, D., Liererman, M., Hartshorn, G. S. and Peralta, R., 1990, Estimation of tropical forest canopy temperatures, thermal response numbers, and evapotranspiration using an aircraft-based thermal sensor. Photogrammetric Engineering and Remote Sensing, 56, 1393-1401.

Matson, M., McClain, E. P., McGinnis, D. F. and Pritchard, J. A., 1978. Satellite detection of urban heat islands. Monthly Weather Retiew, 106, 1725-1734.

MCPherson, E. G., 1994. Cooling urban heat islands with sustainable landscapes. In The Ecological City: Preserving and Restoring Urban Bioditersity, edited by R. H. Platt, R. A. Rowntree, and Pamela C. Muick (Amherst. Ma: The University of Massachusetts Press), pp. 151-171.

Monteith, J. L., 1973, Principles of Environmental Physics (New York: American Elsevier Publishing Company, Inc.), pp. 14-22.

NEMANI, R. R. and RuniNing, S. W., 1989, Estimation of regional surface resistance to evapotranspiration from NDVI and thermal-IR AVHRR data. Journal of Applied Meteorology, 28, 276-284.

NICHOL, J. E., 1994, A GIS-based approach to microclimate monitoring in Singapore's highrise housing estates. Photogrammetric Engineering and Remore Sensing, 60, 1225-1232.

OKE, T. R., 1987, Boundary Layer Climates (London: Routledge), pp. 262-302.

Roth, M., OкE, T. R., and Emery, W. J., 1989, Satellite-derived urban heat islands from three coastal cities and the utilization of such data in urban climatology. International Journal of Remote Sensing, 10, 1699-1720. 